\title{
Lubeluzole Pretreatment Does Not Provide Neuroprotection Against Transient Global Cerebral Ischemia in Fetal Sheep Near Term
}

\author{
YVES GARNIER, THORSTEN LÖBBERT, ARNE JENSEN, AND RICHARD BERGER \\ Department of Obstetrics and Gynecology, Ruhr-Universität Bochum, Bochum, Germany
}

\begin{abstract}
The aim of the present study was to test the neuroprotective effect of the novel benzothiazol compound lubeluzole on neuronal cell damage in fetal sheep arising from global cerebral ischemia. Thirteen fetal sheep were prepared at a mean gestational age of $127 \pm 1 \mathrm{~d}$ (term is at $147 \mathrm{~d}$ ). Six fetuses were treated with lubeluzole $(0.33 \mathrm{mg} / \mathrm{kg}$ estimated body weight $)$ before induction of global cerebral ischemia $(-90,-60$, and $-30 \mathrm{~min})$, while the remainder $(n=7)$ received solvent. Cerebral ischemia was induced by occluding both carotid arteries for $30 \mathrm{~min}$. Cerebral blood flow was measured by injecting radiolabeled microspheres before $(-90 \mathrm{~min})$, during $(+3 \mathrm{~min}$ and $+27 \mathrm{~min})$, and after $(+40 \mathrm{~min},+3 \mathrm{~h}$, and $+72 \mathrm{~h})$ cerebral ischemia. Neuronal cell damage was assessed in the cerebrum and deeper brain structures by light microscopy. Values are given as means \pm SD. In control fetuses, blood flow to the cerebrum was reduced from $100 \pm 25 \mathrm{~mL} \cdot 100 \mathrm{~g}^{-1} \mathrm{~min}^{-1}$ to less than 20 $\mathrm{mL} \cdot 100 \mathrm{~g}^{-1} \mathrm{~min}^{-1}$ during ischemia. Shortly after ischemia, hyperperfusion occurred $\left(217 \pm 66 \mathrm{~mL} \cdot 100 \mathrm{~g}^{-1} \mathrm{~min}^{-1}\right)$ followed by a tendency toward hypoperfusion $\left(72 \pm 17 \mathrm{~mL} \cdot 100 \mathrm{~g}^{-1}\right.$ $\min ^{-1}$ ) later on $(+3 \mathrm{~h})$. Significant differences in blood flow to
\end{abstract}

\section{ABSTRACT}

the various brain structures between the control and study groups could not be observed. Neuronal cell damage was concentrated in the parasagittal regions of the cerebrum. Preischemic application of lubeluzole did not have any effect on the extent of neuronal cell damage. From these results, we conclude that pretreatment with lubeluzole fails to protect the brain of fetal sheep near term from injury after transient global cerebral ischemia. However, because the observation period lasted only $3 \mathrm{~d}$, a possible effect of lubeluzole on pathophysiological mechanisms inducing delayed neuronal cell death cannot be fully excluded. (Pediatr Res 51: 517-522, 2002)
BE, base excess
Abbreviations
FHR, fetal heart rate
MRI, magnetic resonance imaging
NO, nitric oxide
NOS, nitric oxide synthase
$\mathrm{So}_{2}$, oxygen saturation of $\mathrm{Hb}$

Hypoxic-ischemic cerebral damage is an important contributor to perinatal mortality and morbidity including long-term neurologic sequelae in term and preterm fetuses (1). Although over the last decade many therapeutic strategies have been developed in various animal models to reduce neuronal cell damage caused by ischemic insults, their clinical application has often been rejected due to major drug-related side-effects (2). Especially after application of calcium antagonists and inhibitors of NOS, alterations of fetal cardiovascular control have been observed $(3,4)$. However, the recently developed benzothiazole compound lubeluzole seems to justify further research in this field. The neuroprotective efficiency of this drug has been shown in a variety of in vitro as well as in vivo

Received October 25, 2000; accepted September 21, 2001.

Correspondence: Richard Berger, M.D., Universitätsfrauenklinik, Knappschaftskrankenhaus, In der Schornau 23-25, D-44892 Bochum, Germany; e-mail: richard.berger@ruhr-uni-bochum.de

This work was supported by Deutsche Forschungsgemeinschaft and by Janssen Pharmaceutica (Beerse, Belgium). experiments (5-10). In clinical safety studies, severe drugrelated side-effects could be excluded (11). Phase III trials have provided different results. Whereas Grotta (12) described a neuroprotective effect of lubeluzole in patients suffering from acute ischemic stroke, this finding could not be confirmed in other trials $(13,14)$.

The present knowledge on the safety profile and efficiency of lubeluzole seems to be promising enough to warrant further studies in immature animals. Recently, we were able to show that lubeluzole does not affect fetal circulatory centralization during acute asphyxia. This mechanism is of major importance, because it protects the fetal brain from neuronal injury by increasing blood flow to the central organs, i.e. brain, heart, adrenals, when oxygen is in short supply (15). The present study was performed to clarify whether lubeluzole protects the brain of fetal sheep near term from neuronal cell damage. Global cerebral ischemia was induced by occluding both carotid arteries for $30 \mathrm{~min}$. To account for drug-related changes in cerebral blood flow that might affect neuronal cell damage, 
we measured cerebral blood flow using the microspheres method.

\section{METHODS}

Animal preparation. Thirteen fetal sheep were prepared at a mean gestational age of $127 \pm 1 \mathrm{~d}$ (term is at $147 \mathrm{~d}$ ). All ewes were anesthetized by subarachnoid injection of $8 \mathrm{~mL}$ of $0.75 \%$ $(\mathrm{wt} / \mathrm{vol})$ bupivacaine at the lower spine, and were operated under sterile conditions. Polyvinyl catheters were placed in a maternal iliac artery and vein through tibial vessels. The ewe's abdominal wall was opened along the midline and the fetal hindlimbs were exposed through a small uterine incision. Using local anesthesia (prilocaine $\mathrm{HCl} 1.0 \%$ ), polyvinyl catheters were inserted via the pedal vein of each hindlimb into the inferior vena cava. The uterine incision was closed and a second uterine incision was performed over the fetal snout. Head and neck of the fetus were exteriorized. To prevent the fetus from breathing, its head was covered by a water-filled rubber glove. Catheters were inserted into the fetal ascending aorta via both brachial arteries. Furthermore, both fetal common carotid arteries were prepared. Cerebral ischemia was induced by occluding the carotid arteries on both sides simultaneously below the thyroid and above the lingual artery for 30 min as described recently $(16,17)$. Thus, blood flow to the cerebrum via anastomoses between the carotid and vertebral arteries was arrested. After cerebral ischemia, a catheter was inserted into the amniotic cavity, and the second intrauterine incision was closed. All catheters were filled with heparin (1000 IU/mL), plugged, and passed subcutaneously to the ewe's flank, where they were exteriorized and protected by a pouch sewn to the skin. On the day of surgery and each day thereafter, the ewe received 2 million units of penicillin $G$ (Grünenthal, Aachen, Germany) and $80 \mathrm{mg}$ of gentamicin sulfate (Merck, Darmstadt, Germany), half intravenously and half into the amniotic cavity.

Experimental protocol. After insertion of polyvinyl catheters into the inferior vena cava, six fetuses received three bolus injections of lubeluzole at $30 \mathrm{~min}$ intervals $(3 \times 0.11 \mathrm{mg} / \mathrm{kg}$ estimated fetal body weight), while an equal volume $(3 \times 1.3$ $\mathrm{mL}$ ) of the solvent was administered to the remaining fetuses. The drugs were donated by Janssen Pharmaceutica, Beerse, Belgium. The concentration of lubeluzole used in the present study was within the same range as that applied in previous investigations. In humans, the injected dose ranged from 2.5 to $25 \mathrm{mg} / \mathrm{d}$, i.e. about 0.036 to $0.36 \mathrm{mg} / \mathrm{kg} / \mathrm{d}(12,13,18)$, whereas in rats lubeluzole was applied at a concentration of between 0.62 and $0.8 \mathrm{mg} / \mathrm{kg}(9,10,19)$. In vitro studies have even shown that lubeluzole has neuroprotective effects down to the picomolar range (molecular weight: 43,352 g/mol) (7). In preliminary experiments, we applied lubeluzole to fetal sheep by a single i.v. injection at a concentration of $0.33 \mathrm{mg} / \mathrm{kg}$. This resulted in alterations of FHR as well as arterial hypotension. We therefore considered the dosage applied in the present study to be at the upper limit of the therapeutic range in fetal sheep near term. A further increase in the administered concentration might have altered fetal cardiovascular control and would therefore have interfered with a possible neuroprotective effect of lubeluzole.

Cerebral ischemia was induced $30 \mathrm{~min}$ after the final injection of lubeluzole. To determine the time course of changes in fetal cerebral blood flow, six batches of differently isotopelabeled microspheres $\left({ }^{113} \mathrm{Sn},{ }^{103} \mathrm{Ru},{ }^{46} \mathrm{Sc},{ }^{114} \mathrm{In},{ }^{141} \mathrm{Ce}\right.$, and ${ }^{95} \mathrm{Nb}, 16 \mu \mathrm{m}$ diameter, New England Nuclear, Boston, MA, U.S.A.) were used. The microspheres, suspended in $10 \%$ dextran containing $0.01 \%$ Tween 80 , were sonicated and checked for size, shape, and aggregation. Depending on the specific activity, 1.2-1.8 million microspheres per batch were injected into the inferior vena cava before $(-90 \mathrm{~min})$, during $(+3 \mathrm{~min}$ and $+27 \mathrm{~min})$, and after $(+40 \mathrm{~min},+3 \mathrm{~h}$, and $+72 \mathrm{~h}) 30 \mathrm{~min}$ of cerebral ischemia. The number of injected microspheres was large enough to ensure both an adequate number of microspheres per sample and valid blood flow measurements during cerebral ischemia $(20,21)$. Specific calculations revealed that about 400 microspheres were trapped in low-flow cerebral areas during ischemia. Thus, for theoretical considerations, the blood flow estimates in these areas are within $5 \%$ of the true values (20). During and shortly after injection of the microspheres no significant changes in FHR or arterial blood pressure were found. Reference blood samples were withdrawn from the brachial artery at a rate of $2.5 \mathrm{~mL} \cdot \mathrm{min}^{-1}$ for $90 \mathrm{~s}(16$, 17). The volume of blood withdrawn was about $22.5 \mathrm{~mL}$ and was simultaneously replaced by maternal blood maintained at $39^{\circ} \mathrm{C}$ in a water bath.

During and shortly after cerebral ischemia FHR, ascending aortic and intrauterine pressure were recorded simultaneously. After having injected the fourth batch of microspheres (at +40 min) all catheters were closed and secured as described above, the abdominal wall was closed and the ewe was brought back to the metabolic cage, where the fifth injection (at $+3 \mathrm{~h}$ ) was performed. For technical reasons, there were no pressure measurements at this point in time. Before each injection, blood samples were obtained from the brachial artery to measure blood gases, $\mathrm{So}_{2}$, and acid-base balance. At the end of the experiment (at $+72 \mathrm{~h}$ ), the ewe was given a lethal dose of sodium pentobarbitone and saturated potassium chloride intravenously, and the fetus was perfused with $300 \mathrm{~mL}$ of formalin (15\%, wt/vol, saline).

The experimental protocols were approved by the appropriate institutional review committee and met the guidelines of the governmental agency responsible.

Measurements. Ascending aortic and intrauterine pressure, and FHR were recorded on a polygraph (Hellige, Freiburg, Germany). Blood gases and $\mathrm{pH}$ were measured in an automatic blood gas analyzer (278 Blood Gas System, Ciba Corning, Frankfurt, Germany), and BE was calculated. Hb concentration and oxygen saturation of $\mathrm{Hb}$ were measured photometrically (OSM 2 Hemoximeter, Radiometer, Copenhagen, Denmark) in duplicate.

Fetal cerebral blood flow and the extent of neuronal cell damage were assessed in identical brain specimens. To determine fetal cerebral blood flow using the microspheres method, the fetal brain was removed and fixed in formalin for at least $7 \mathrm{~d}$. Afterward, the cerebrum was separated from the basal ganglia and divided into four frontal sections (rostral, pericen- 
tral, postcentral, occipital) with a thickness of about $1.5 \mathrm{~cm}$. The right and left parts of these four sections were further subdivided into four equal segments (parasagittal 1 and 2, lateral 1 and 2) each weighing 1-2 g. In addition to these 32 cerebral specimens, caudate nucleus, thalamus, hippocampus, tegmentum-colliculi-pons, cerebellum, and medulla oblongata were separated. These brain structures were placed in vials, which were filled to the same height to reduce variations in geometry during gamma counting.

After cerebral blood flow analysis, the specimens of the fetal brain were removed from the counting vials and embedded in paraffin. Coronal subserial sections of $10 \mu \mathrm{m}$ were obtained and stained with cresyl violet/fuchsin. Every 40th section was mounted to evaluate the extent of neuronal cell damage. Neuronal cell damage was assessed at a magnification of $250 \times$. Neurons with ischemic cell damage were identified according to the criteria of Brown and Brierley (22). Neuronal cell damage in each microscopical visual field was quantified by the following score: $0-5 \%$ damage (score 1), 5-50\% damage (score 2), 50-95\% damage (score 3), 95-99\% damage (score 4), and 100\% damage (score 5). In the present investigation, a scoring system was preferred, inasmuch as evaluation of neuronal cell loss by neuron counts was unfeasible due to the considerable number of histologic sections studied. As assessed by the coefficient of variation, the intra- and interobserver reliability of this procedure was $4 \%$ and $10 \%$, respectively (17).

Calculations. Fetal cerebral blood flow was calculated from counts of the injected nuclide recovered in the fetal cerebrum and the appropriate reference sample, and from the withdrawal rate of the reference sample $(16,17)$. The histologic score of each cerebral specimen was calculated by averaging the scores of all visual fields analyzed from three sections of that specimen. The number of visual fields evaluated per specimen ranged between 400 and 500 each. The scores from corresponding specimens from the right and left hemisphere were averaged.
Statistics. Values are given as means $\pm \mathrm{SD}$. The data were analyzed for intra- and intergroup differences by two-way multivariate ANOVA for repeated measures. The GamesHowell test was used as a posthoc testing procedure.

\section{RESULTS}

The physiologic variables of the control and study groups before, during, and after 30 min of global cerebral ischemia are shown in Table 1. Before injection of lubeluzole or carrier no significant differences in these variables were found between the control and study groups. At control, the plasma concentrations of both glucose and lactate were slightly above the normal range for chronically prepared fetal sheep (23), but had normalized by the end of the experiments.

Under control conditions, blood flow to the cerebrum averaged $100 \pm 25 \mathrm{~mL} \cdot 100 \mathrm{~g}^{-1} \mathrm{~min}^{-1}$ and was reduced by more than $80 \%$ after carotid blood flow had been arrested. In the immediate recovery period, i.e. $10 \mathrm{~min}$ after ischemia, hyperperfusion occurred followed by a variable hypoperfusion later on $(+3 \mathrm{~h})$. Finally, at $72 \mathrm{~h}$ after ischemia, blood flow to the cerebrum was higher than at control $(p \leq 0.05)$. This pattern of dynamic changes in blood flow could be observed in each of the 32 cerebral specimens studied as well as in almost all deeper brain structures. Differences between the control and study groups could not be detected (Table 2). This was also true for each of the 32 cerebral specimens.

Neuronal cell damage was most pronounced in the parasagittal regions, whereas in the more lateral part of the cortex only minor neuronal damage could be seen (Table 3). Furthermore, cell damage was observed in the cerebellum, hippocampus, and caudate nucleus (Table 4). There were almost no significant differences in neuronal cell damage in any parts of the cerebrum or deeper brain structures between treated and untreated fetuses (Tables 3 and 4).

Table 1. Physiological variables, acid-base balance, and blood gases before, during, and after transient global cerebral ischemia in fetal

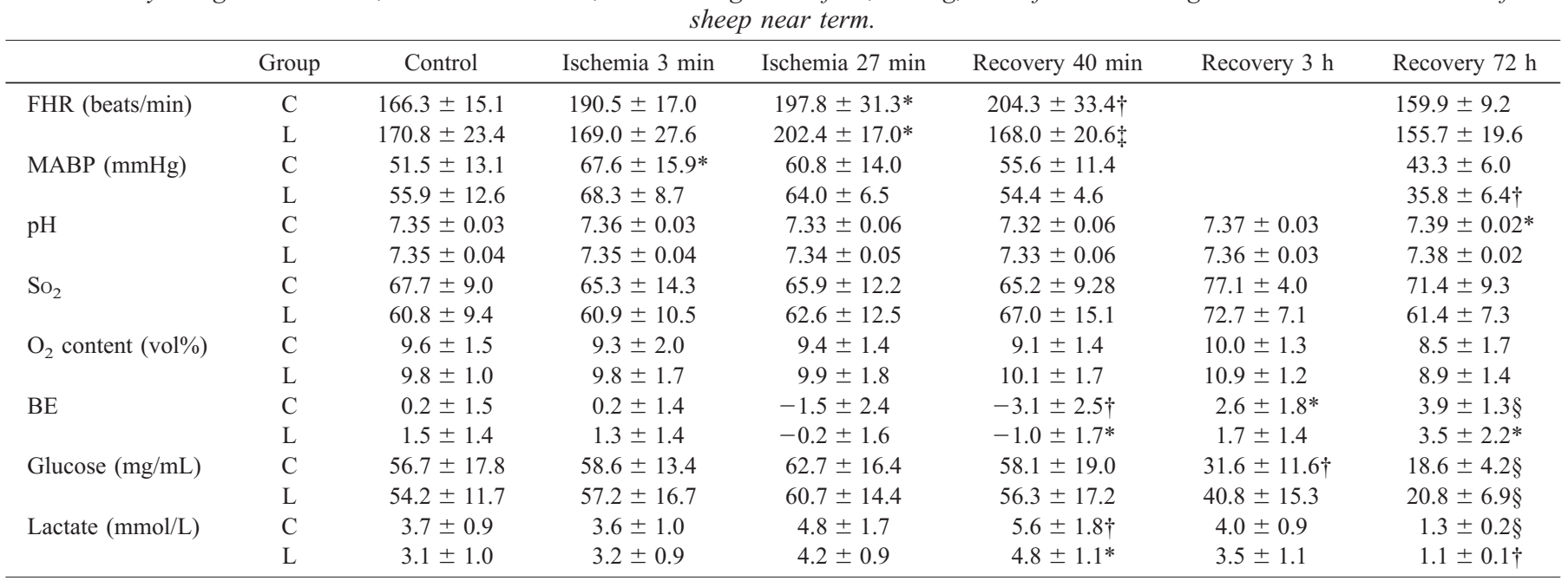

Values are given as means $\pm \mathrm{SD}$.

$\mathrm{C}$, untreated fetuses $(n=7)$; L, treated fetuses (lubeluzole; $n=6$ ); MABP, mean arterial blood pressure. Values are given as means $\pm \mathrm{SD}$.

Significant differences between groups: $\ddagger p<0.01$; significant differences within groups $v s$. time point "control": $* p<0.05, \dagger p<0.01, \S p<0.001$. 
Table 2. Blood flow to various brain areas before, during, and after transient global cerebral ischemia in fetal sheep near term

\begin{tabular}{|c|c|c|c|c|c|c|c|}
\hline \multicolumn{8}{|c|}{ Organ blood flows $(\mathrm{mL} / \mathrm{min} / 100 \mathrm{~g})$} \\
\hline & Group & Control & Ischemia $3 \mathrm{~min}$ & Ischemia $27 \mathrm{~min}$ & Recovery $40 \mathrm{~min}$ & Recovery $3 \mathrm{~h}$ & Recovery $72 \mathrm{~h}$ \\
\hline Brain total & $\mathrm{C}$ & $141.1 \pm 35.7$ & $23.6 \pm 11.4^{*}$ & $34.8 \pm 13.5^{*}$ & $309.5 \pm 77.8^{*}$ & $106.7 \pm 25.2$ & $227.0 \pm 45.7^{*}$ \\
\hline \multirow[t]{2}{*}{ Cerebrum } & $\mathrm{C}$ & $100.2 \pm 24.7$ & $15.7 \pm 7.8^{*}$ & $22.3 \pm 11.0^{*}$ & $217.0 \pm 65.6^{*}$ & $72.1 \pm 16.6$ & $160.9 \pm 34.9 \dagger$ \\
\hline & $\mathrm{L}$ & $102.9 \pm 34.1$ & $8.6 \pm 7.4^{*}$ & $16.7 \pm 6.5^{*}$ & $198.6 \pm 62.2 *$ & $71.6 \pm 24.6$ & $163.8 \pm 51.2 \dagger$ \\
\hline \multirow[t]{2}{*}{ Cerebellum } & $\mathrm{C}$ & $151.2 \pm 64.4$ & $27.1 \pm 19.6 \dagger$ & $49.7 \pm 22.6 \dagger$ & $413.6 \pm 146.8^{*}$ & $163.8 \pm 67.6$ & $261.3 \pm 85.6 \dagger$ \\
\hline & $\mathrm{L}$ & $156.4 \pm 56.7$ & $19.2 \pm 16.1^{*}$ & $38.0 \pm 10.3 \dagger$ & $335.7 \pm 67.1 * \vdots$ & $131.4 \pm 30.3$ & $261.1 \pm 84.2 \S$ \\
\hline Hippocampus & $\mathrm{L}$ & $101.1 \pm 31.6$ & $15.9 \pm 13.5^{*}$ & $27.2 \pm 16.5^{*}$ & $177.7 \pm 36.8 * \mathbb{q}$ & $70.8 \pm 28.6$ & $168.0 \pm 43.1 \dagger$ \\
\hline \multirow[t]{2}{*}{ Caudate nucleus } & $\mathrm{C}$ & $120.8 \pm 33.9$ & $33.4 \pm 27.2 \dagger$ & $37.7 \pm 15.0 \dagger$ & $264.9 \pm 89.0^{*}$ & $94.2 \pm 32.0$ & $198.6 \pm 90.1 \dagger$ \\
\hline & $\mathrm{L}$ & $116.2 \pm 32.4$ & $8.9 \pm 4.1^{*}$ & $27.1 \pm 9.3 \dagger$ & $217.2 \pm 67.8^{*}$ & $90.2 \pm 33.0$ & $194.9 \pm 63.2 \dagger$ \\
\hline \multirow[t]{2}{*}{ Medulla oblongata } & $\mathrm{C}$ & $201.4 \pm 56.3$ & $61.4 \pm 28.2 *$ & $67.8 \pm 30.8 \dagger$ & $254.4 \pm 145.5$ & $199.7 \pm 73.7$ & $354.2 \pm 82.8^{*}$ \\
\hline & $\mathrm{L}$ & $196.5 \pm 69.0$ & $37.4 \pm 21.6^{*}$ & $51.8 \pm 14.6 \dagger$ & $234.6 \pm 122.5$ & $147.9 \pm 41.0$ & $312.1 \pm 79.2 \dagger$ \\
\hline
\end{tabular}

C, untreated fetuses $(n=7)$; L, treated fetuses (lubeluzole; $n=6$ ). Values are given as means $\pm \mathrm{SD}$.

Significant differences between groups: $\ddagger p<0.05$; $₫ p<0.01$; significant differences within groups $v$ s. time point "control”: $\S p<0.05, \dagger p<0.01,{ }^{*} p<$ 0.001 .

Table 3. Neuronal cell damage in the cerebrum of fetal sheep near term $72 \mathrm{~h}$ after global cerebral ischemia

\begin{tabular}{|c|c|c|c|c|c|}
\hline & & \multicolumn{4}{|c|}{ Segments } \\
\hline & & \multicolumn{2}{|c|}{ Parasagittal } & \multicolumn{2}{|c|}{ Lateral } \\
\hline & & 1 & 2 & 1 & 2 \\
\hline Frontal & $\mathrm{L}$ & $1.72 \pm 0.63$ & $1.68 \pm 0.67$ & $1.72 \pm 0.69$ & $1.75 \pm 0.71$ \\
\hline \multirow[t]{2}{*}{ Pericentral } & $\mathrm{C}$ & $2.49 \pm 0.97$ & $1.93 \pm 0.70$ & $1.58 \pm 0.89^{*}$ & $1.16 \pm 0.38^{* *}$ \\
\hline & $\mathrm{L}$ & $2.38 \pm 1.01$ & $2.10 \pm 1.07$ & $1.64 \pm 0.59$ & $1.42 \pm 0.47^{*}$ \\
\hline \multirow[t]{2}{*}{ Occipital } & $\mathrm{C}$ & $2.18 \pm 1.35$ & $2.33 \pm 1.36$ & $2.17 \pm 1.24$ & $1.94 \pm 1.13$ \\
\hline & $\mathrm{L}$ & $2.06 \pm 0.84$ & $2.13 \pm 0.85$ & $2.07 \pm 0.82$ & $1.88 \pm 0.75$ \\
\hline
\end{tabular}

C, untreated fetuses $(n=7)$; L, treated fetuses (lubeluzole; $n=6$ ). Values are given as means $\pm \mathrm{SD}$.

$* p \leq 0.05 ; * * \leq 0.01$ : parasagittal segment 1 vs. pericentral. \# $p \leq 0.05$; \#\# $p \leq 0.01$ : parasagittal segment 1 vs. postcentral.

Table 4. Neuronal cell damage in various areas of the diencephalon, mesencephalon, and brain stem in fetal sheep near term $72 \mathrm{~h}$ after 30 min of global cerebral ischemia

$\begin{array}{lll}\text { Cerebellum } & \text { C } & 1.41 \pm 0.42 \\ \text { Hippocampus } & \text { L } & 1.65 \pm 0.40 \\ \text { Caudate nucleus } & \text { C } & 1.71 \pm 0.71 \\ \text { Medulla } & \text { L } & 2.22 \pm 0.57 \\ & \text { C } & 1.10 \pm 0.11 \\ & \text { L } & 1.21 \pm 0.15 \\ & \text { C } & 1.00 \pm 0.00 \\ & \text { L } & 1.00 \pm 0.00\end{array}$

C, untreated fetuses ( $n=7$ ); L, treated fetuses (lubeluzole; $n=6$ ). Values are given as means \pm SD. Significant differences between groups could not be detected.

\section{DISCUSSION}

Lubeluzole, the S-isomer of a novel 3,4-difluoro benzothiazole, has been shown to reduce ischemic neuronal cell damage in a variety of in vitro as well as in vivo studies. The neuroprotective property of lubeluzole may result from various effects on neuronal tissue. First, lubeluzole has been shown to block ischemia-induced increases in extracellular levels of glutamate and may therefore reduce excitotoxic cell injury (24). Second, lubeluzole inhibits glutamate-stimulated NO production (25). NO combines with superoxide anions to synthesize peroxynitrite, a compound that spontaneously decomposes to form hydroxyl radicals, nitrogen dioxide, and $\mathrm{NO}^{2+}$. All these radicals are able to destroy cell membranes and various intracellular structures. Third, lubeluzole has been shown to activate voltage-sensitive $\mathrm{Ca}^{2+}$ channels in isolated rat dorsal root ganglion cells, thus possibly reducing the tremendous intracellular influx of this ion during an ischemic insult (26). This so-called calcium overload leads to cell damage by activating proteases, lipases, and endonucleases (27). Fourth, lubeluzole decreased DNA fragmentation and annexin- $\mathrm{V}$ binding in primary hippocampal neurons $(28,29)$. Because these two phenomena are specific markers of apoptosis, lubeluzole might protect neurons from ischemic injury through its inhibitory effects on pathophysiological pathways that trigger the cellular suicide program. However, these last three lubeluzolemediated effects have so far only been observed in neuronal tissue in vitro. Their in vivo significance has still to be confirmed.

Unfortunately, in the present study we were unable to show any neuroprotective effect of lubeluzole on neuronal cell damage in fetal sheep near term after global ischemia. This appears to be inconsistent with various investigations on adult animals (5-10). However, in almost all of these studies models of focal cerebral ischemia were used (5-9). This type of cerebral ischemia is characterized by an ischemic core and a peri-infarct region known as ischemic penumbra $(30,31)$. In this area, brain tissue is perfused at a level between the thresholds of functional impairment and of morphologic integrity. Unless 
cerebral blood flow is rapidly improved in this region within a few hours after the insult, neuronal cell damage is the inevitable result $(30,31)$. As shown in previous studies, glutamate is released in tremendous amounts from the infarct core into the extracellular space after focal ischemia. Increases of up to 80 times above baseline levels have been observed (32). The released glutamate activates the neuronal NOS via calcium influx through $N$-methyl-D-aspartate (NMDA)-regulated calcium channels $(33,34)$. In focal ischemia, this pathway may be of greater importance for the development of neuronal cell damage than in global ischemia, since in the latter type of ischemia only a moderate and short-lasting increase in glutamate release has been observed $(35,36)$. This may explain, in part, the differences in neuronal outcome between the present study and previous investigations after treatment of brain injury by lubeluzole. In addition, many other pathophysiological mechanisms such as inhibition of protein synthesis, generation of epileptogenic impulses, etc. are differently regulated in focal and global ischemia and may therefore alter the neuroprotective efficiency of lubeluzole (37-41).

However, there is one study in adult rats indicating that lubeluzole protects the brain from neuronal cell loss after global ischemia (10). Posttreatment with lubeluzole significantly increased the number of viable neurons in the hippocampus. There could be a number of reasons for the difference in neuronal outcome between this study and our experiments. First, the postischemic pattern of pathophysiological changes in the immature brain may not be the same as in the adult. For example, glutamate release has been reported to be significantly lower in neonates than in adults (42). Although glutamate toxicity has been reported in fetal sheep after cerebral ischemia, this may also affect the induction of NOS via NMDA-receptor regulated calcium channels. Because the neuroprotective properties of lubeluzole are mediated, in part, by its effects on the NO system (25), this may explain the differences in neuronal outcome between the present study and that of Haseldonckx (10). Furthermore, inhibition of the NOS in the fetal sheep had no influence on neuronal cell damage, indicating that NO release may not play a major pathophysiological role in the development of brain injury under these conditions (43). Second, in our study, lubeluzole was injected before cerebral ischemia, whereas Haseldonckx and co-workers (10) applied the drug shortly after the insult. One might therefore speculate that bolus injection of lubeluzole before ischemia results in an insufficient drug supply during the postischemic period. However, as demonstrated in patients with acute ischemic stroke, the mean terminal half-life of this compound in the plasma is $27.7 \mathrm{~h}$ (18). Thus, application of lubeluzole $1 \mathrm{~h}$ before ischemia guarantees postischemic plasma concentrations that are within the therapeutic range. When designing the present study, a pretreatment protocol was chosen, inasmuch as we considered this to be more effective than a posttreatment strategy. Especially under clinical conditions, pretreatment of babies at risk of hypoxic-ischemic encephalopathy by maternal application of various neuroprotective drugs would seem conceivable. Whether an additional application of lubeluzole after cerebral ischemia provides neuroprotection in the present experimental model will have to be examined in further investi- gations. Third, the end point in our study and that of Haseldonckx and co-workers was different. Whereas neuronal cell damage was evaluated only $3 \mathrm{~d}$ after the insult in the present investigation, it was not assessed until $7 \mathrm{~d}$ after cerebral ischemia in the latter study. Unfortunately, the sheep model does not allow for longer postischemic observation periods, inasmuch as this would result in a tremendous increase in the abortion rate due to intrauterine infection and fetal distress. It is conceivable that even several days after the ischemic insult the continued activation of the inducible form of NOS in astrocytes and microglia might result in an increased production of NO (44). One might therefore object that delayed neuronal cell death due to an increased NO production cannot be evaluated using this model (45-47). Because modulation of NO toxicity is a probable target for lubeluzole (25), the negative result of the present study might be due to this phenomenon. This objection cannot be fully excluded. However, as mentioned above, NO toxicity may not play any major part in the development of neuronal cell death in this model, inasmuch as inhibition of the NO system had no effect on brain injury (43). Furthermore, as shown in a recent study using the MRI technique, neuroprotective effects of lubeluzole can already be observed within a few hours after ischemia (9). If the main target of lubeluzole is NO toxicity, then a neuroprotective effect should have been observed as early as $3 \mathrm{~d}$ after ischemia as demonstrated in a recent study on neonatal rats using an inhibitor of the NOS (48). To exclude very delayed neuroprotective effects of lubeluzole on the neuropathologic outcome in immature animals, additional experiments will have to be performed using other ischemic models, e.g. unilateral carotid occlusion in the neonatal rat $(49,50)$. However, it should be taken into account that drug-related side effects of various neuroprotective substances, such as lubeluzole, on the cardiovascular system cannot be monitored in such small animals. We therefore feel that in a first approach, the present model was highly appropriate for investigation of the neuroprotective efficacy of lubeluzole.

As already shown for a variety of other drugs (for review, Ref. 40), the neuroprotective properties of lubeluzole might depend on the type of ischemia studied and the animal model used. It is therefore conceivable that lubeluzole might protect the fetal brain from ischemic insults in animal models of systemic asphyxia induced by occlusion of the umbilical cord or the uterine arteries. Neuronal loss has been observed after repetitive cord occlusion in the striatum, an area with high glutaminergic input (51). Inasmuch as lubeluzole is known to inhibit glutamate release during an ischemic insult (24), this drug may be neuroprotective in such an animal model. However, when brain injury is induced by systemic asphyxia, the extent and location of neuronal cell loss often vary widely (52-54) and there is a considerable rise in the fetal abortion rate. Because hardly any neuroprotective effect can be demonstrated under such conditions, we preferred the fetal sheep model of global cerebral ischemia caused by occlusion of both carotid arteries. The fact that lubeluzole did not appear to have any neuroprotective effect in the present model cannot be attributed to a lack of glutamate toxicity. As already shown in a previous study the application of MK-801 after global cere- 
bral ischemia caused a significant improvement in neuropathological outcome in fetal sheep (55).

From the present results, we conclude that pretreatment with lubeluzole fails to protect the brain of fetal sheep near term from injury after transient global cerebral ischemia. However, because the observation period lasted only $3 \mathrm{~d}$, a possible effect of lubeluzole on pathophysiological mechanisms inducing delayed neuronal cell death cannot be fully excluded.

Acknowledgments. The authors thank Otmar Adam, Dorothea Ehler, and Monika Nickel for their excellent technical assistance.

\section{REFERENCES}

1. Volpe JJ 1995 Neurology of the Newborn. Saunders, Philadelphia

2. Wangen K, Myhrer T, Moldstad JN, Iversen EG, Fonnum F 1997 Modulatory treatment of NMDA receptors in neonatal rats affects cognitive behavior in adult age. Brain Res Dev Brain Res 99:126-130

3. Green LR, Bennet L, Hanson MA 1996 The role of nitric oxide synthesis in cardiovascular responses to acute hypoxia in the late gestation sheep fetus. J Physiol 497:271-277

4. Gunn AJ, Williams CE, Mallard EC, Tan WKM, Gluckman PD 1994 Flunarazine, a calcium channel antagonist, is partially prophylactically neuroprotective in hypoxic/ ischemic encephalopathy in the fetal sheep. Pediatr Res 35:657-663

5. Aranowski J, Strong R, Grotta JC 1996 Combined neuroprotection and reperfusion therapy for stroke. Effect of lubeluzole and diaspirin cross-linked hemoglobin in experimental focal ischemia. Stroke 27:1571-1577

6. Buchkremer-Ratzmann I, Witte OW 1997 Pharmacological reduction of electrophysiological diaschisis after photothrombotic ischemia in rat neocortex. Eur J Pharmacol 320:103-109

7. Culmsee C, Junker V, Wolz P, Semkova I, Krieglstein J 1998 Lubeluzole protects hippocampal neurons from excitotoxicity in vitro and reduces brain damage caused by ischemia. Eur J Pharmacol 342:193-201

8. De Ryck M, Scheller D, Clincke G, Janssen M, Van Reet S 1995 Lubeluzole, a novel benzothiazole, protects neurologic function, reduces infarct size, and blocks periinfarct glutamate rise after cerebral thrombotic stroke in rats. Cerebrovasc Res 5:264

9. De Ryck M, Verhoye M, Van der Linden M 2000 Diffusion-weighted MRI of infarct growth in a rat photochemical stroke model: effect of lubeluzole. Neuropharmacology 39:691-702

10. Haseldonckx M, Van Reempts J, Van de Ven M, Wouters L, Borgers M 1997 Protection with lubeluzole against delayed ischemic brain damage in rats. A quantitative histopathologic study. Stroke 28:428-432

11. Diener HC, Hacke W, Hennerici M, Rådberg J, Hantson L, De Keyser J 1996 Lubeluzole in acute ischemic stroke. A double-blind, placebo-controlled Phase II trial. Stroke 27:76-81

12. Grotta J 1997 Lubeluzole treatment of acute ischemic stroke. The US and Canadian Lubeluzole Ischemic Stroke Group. Stroke 28:2338-2346

13. Diener HC 1998 Multinational randomised controlled trial of lubeluzole in acute ischaemic stroke. European and Australian Lubeluzole Ischaemic Stroke Study Group. Cerebrovasc Dis 8:172-181

14. Diener HC, Cortens M, Ford G, Grotta J, Hacke W, Kaste M, Koudstaal M, Wessel T 2000 Lubeluzole in acute ischemic stroke treatment: a double blind study with an 8 -hour inclusion window comparing a $10-\mathrm{mg}$ daily dose of lubeluzole with placebo. Stroke 31:2543-2551

15. Berger R, Garnier Y, Löbbert T, Pfeiffer D, Jensen A 2001 Circulatory responses to acute asphyxia are not affected by the glutamate antagonist lubeluzole in fetal sheep near term. J Soc Gynecol Investig 8:143-148

16. Berger R, Lehmann T, Karcher J, Garnier Y, Jensen A 1998 Low dose flunarizine protects the fetal brain from ischemic injury in sheep. Pediatr Res 44:1-6

17. Berger R, Lehmann T, Karcher J, Schachenmayr W, Jensen A 1996 Relation between cerebral oxygen delivery and neuronal cell damage in fetal sheep near term. Reprod Fertil Dev 8:317-321

18. De Keyser J, van de Velde V, Schellens RLLA, Hantson L, Tritsmans L, Gheuens J, van Peer A, Woestenborghs R, Franke CL, van Gorp J 1997 Safety and pharmacokinetics of the neuroprotective drug lubeluzole in patients with ischemic stroke. Clin Ther 19:1340-1351

19. Kroppenstedt SN, Stroop R, Kern M, Thomale UW, Schneider GH, Unterberg AW 1999 Lubeluzole following traumatic brain injury in the rat. J Neurotrauma 16:629-637

20. Buckberg GD, Luck JC, Payne DB, Hoffmann JL, Archie JP, Fixler DE 1971 Some sources of error in measuring regional blood flow with radioactive microspheres. J Appl Physiol 31:598-604

21. Jensen A, Hohmann M, Künzel W 1987 Dynamic changes in organ blood flow and oxygen consumption during acute asphyxia in fetal sheep. J Dev Physiol 9:534-559

22. Brown AW, Brierley JB 1971 Anoxic-ischaemic cell change in rat brain light microscopic and fine structural observations. J Neurol Sci 16:59-84

23. Jensen A, Berger R 1991 Fetal circulatory responses to oxygen lack. J Dev Physiol 16:181-207

24. Scheller D, De Ryck M, Kolb J, Szathmary S, Van Reempts J, Clincke B, Tegtmeier F 1997 Lubeluzole blocks increases in extracellular glutamate and taurine in the peri-infarct zone in rats. Eur J Pharmacol 338:243-251
25. Lesage AS, Peeters L, Leysen JE 1996 Lubeluzole, a novel long-term neuroprotectant, inhibits the glutamate-activated nitric oxide synthase pathway. J Pharmacol Exp Ther 279:759-766

26. Marannes R, De Prins E 2000 Site of action of lubeluzole on voltage-sensitive $\mathrm{Ca}^{(2+)}$ channels in isolated dorsal root ganglion cells of the rat: influence of $\mathrm{pH}$. J Pharmacol Exp Ther 295:531-545

27. Siesjö BK, Bengtsson F 1989 Calcium fluxes, calcium antagonists, and calciumrelated pathology in brain ischemia, hypoglycemia, and spreading depression: a unifying hypothesis. J Cereb Blood Flow Metab 9:127-140

28. Maiese K, Vincent AM 2000 Critical temporal modulation of neuronal programmed cell injury. Cell Mol Neurobiol 20:383-400

29. Maiese K, Vincent AM 2000 Membrane asymmetry and DNA degradation: functionally distinct determinants of neuronal programmed cell death. J Neurosci Res 2000 59:568-580

30. Astrup J, Siesjö BK, Symon I 1981 Thresholds in cerebral ischemia: the ischemic penumbra. Stroke 12:723-725

31. Heiss WD, Graf R 1994 The ischemic penumbra. Curr Opin Neurol 7:11-19

32. Hillered L, Hallstrom A, Segersvard S, Persson L, Ungerstedt U 1989 Dynamics of extracellular metabolites in the striatum after middle cerebral artery occlusion in the rat monitored by intracerebral microdialysis. J Cereb Blood Flow Metab 9:607-616

33. East SJ, Garthwaite J 1991 NMDA receptor activation in rat hippocampus induces cGMP formation through the L-arginine-nitric oxide pathway. Neurosci Lett 123:17-19

34. Southam E, East SJ, Garthwaite 1991 Excitatory amino acid receptors coupled to the nitric oxide/cyclic GMP pathway in rat cerebellum during development. J Neurochem 56:2072-2081

35. Hagberg H, Andersson P, Kjellmer I, Thiringer K, Thordstein M 1987 Extracellular overflow of glutamate, aspartate, GABA and taurine in the cortex and basal ganglia of fetal lambs during hypoxia-ischemia. Neurosci Lett 78:311-317

36. Tan WK, Williams CE, During MJ, Mallard CE, Gunning MI, Gunn AJ, Gluckman PD 1996 Accumulation of cytotoxins during the development of seizures and edema after hypoxic-ischemic injury in late gestation fetal sheep. Pediatr Res 39:791-797

37. Back T, Kohno K, Hossmann KA 1994 Cortical negative DC deflections following middle cerebral artery occlusion and KCl-induced spreading depression: effect on blood flow, tissue oxygenation, and electroencephalogram. J Cereb Blood Flow Metab 14:12-19

38. Back T, Ginsberg MD, Dietrich WD, Watson BD 1996 Induction of spreading depression in the ischemic hemisphere following experimental middle cerebral artery occlusion: effect on infarct morphology. J Cereb Blood Flow Metab 16:202-213

39. Bodsch W, Barbier A, Oehmichen M, Grosse Ophoff B, Hossmann KA 1986 Recovery of monkey brain after prolonged ischemia. II. Protein synthesis and morphological alterations. J Cereb Blood Flow Metab 6:22-33

40. Hossmann K-A 1994 Mechanisms of ischemic injury: is glutamate involved? In: Krieglstein J, Oberpichler-Schwenk H (eds) Pharmacology of Cerebral Ischemia. Wissenschaftliche Verlagsgesellschaft GmbH, Stuttgart, 1994, pp 239-251

41. Mies G, Ishimaru S, Xie Y, Seo K, Hossmann KA 1991 Ischemic thresholds of cerebral protein synthesis and energy state following middle cerebral artery occlusion in rat. J Cereb Blood Flow Metab 11:753-761

42. Berger R, Jensen A, Hossmann K-A, Paschen W 1998 Effect of mild hypothermia during and after transient in vitro ischemia on metabolic disturbances in hippocampal slices at different stages of development. Dev Brain Res 105:67-77

43. Marks KA, Mallard CE, Roberts I, Williams CE, Gluckman PD, Edwards AD 1996 Nitric oxide synthase inhibition attenuates delayed vasodilation and increases injury after cerebral ischemia in fetal sheep. Pediatr Res 40:185-191

44. Endoh M, Maiese K, Wagner J 1994 Expression of the inducible form of nitric oxide synthase by reactive astrocytes after transient global ischemia. Brain Res 651:92-100

45. Kohno K, Ohta S, Kohno K, Kumon Y, Mitani A, Sakaki S, Kataoka K 1996 Nitric oxide synthase inhibitor reduces delayed neuronal death in gerbil hippocampal CA1 neurons after transient global ischemia without reduction of brain temperature or extracellular glutamate concentration. Brain Res 738:275-280

46. Lei B, Adachi N, Nagaro T, Arai T, Koehler RC 1999 Nitric oxide production in the CA1 field of the gerbil hippocampus after transient forebrain ischemia: effects of 7-nitroindazole and NG-nitro-L-arginine methyl ester. Stroke 30:669-677

47. Nanri K, Montecot C, Springhetti V, Seylaz J, Pinard E 1998 The selective inhibitor of neuronal nitric oxide synthase, 7-nitroindazole, reduces the delayed neuronal damage due to forebrain ischemia in rats. Stroke 29:1248-1253

48. Tsuji M, Higuchi Y, Shiraishi K, Kume T, Akaike A, Hattori H 2000 Protective effect of aminoguanidine on hypoxic-ischemic brain damage and temporal profile of brain nitric oxide in neonatal rat. Pediatr Res 47:79-83

49. Levine S 1960 Anoxic-ischemic encephalopathy in rats. Am J Pathol 36:1-17

50. Rice JE, Vanucci RC, Brierley JB 1981 The influence of immaturity on hypoxicischemic brain damage in the rat. Ann Neurol 9:131-141

51. Mallard EC, Waldvogel HJ, Williams CE, Faull RLM, Gluckman PD 1995 Repeated asphyxia causes loss of striatal projection neurons in the fetal sheep brain. Neuroscience 65:827-836

52. de Haan HH, Van Reempts JL, Vles JS, de Haan J, Hasaart TH 1993 Effects of asphyxia on the fetal lamb brain. Am J Obstet Gynecol 169:1493-1501

53. Ikeda T, Murata Y, Quilligan EJ, Parer JT, Murayama T, Koono M 2000 Histologic and biochemical study of the brain, heart, kidney, and liver in asphyxia caused by occlusion of the umbilical cord in near-term fetal lambs. Am J Obstet Gynecol 182:449-457

54. Penning DH, Grafe MR, Hammond R, Matsuda Y, Patrick J, Richardson B 1994 Neuropathology of the near-term and midgestation ovine fetal brain after sustained in utero hypoxemia. Am J Obstet Gynecol 170:1425-32

55. Tan WKM, Williams CE, Gunn AJ, Mallard CE, Gluckman PD 1992 Suppression of postischemic epileptiform activity with MK-801 improves neural outcome in fetal sheep. Ann Neurol 32:677-682 